\title{
Peer-led Research Methods Workshop for First-year Ph.D. Students (Student Paper)
}

\author{
Mr. Vincent Joseph Tocco Jr., University of Florida \\ Graduate Student in Chemical Engineering at the University of Florida.
}

\section{Mr. Kevin Buettner}

Ms. Madeline G Sciullo, University of Florida

Madeline Sciullo is a 4th year Ph.D. Candidate studying Electrical and Computer Engineering at the University of Florida under the appointment of Dr. Mark Law. Her research interests include device physics and simulation on III-V and Silicon based sensors for various application ranging from $\mathrm{pH}$ sensors, mechanical stress effects, to radiation effects of transistors. She is expected to graduate in 2018.

\section{Dr. Jennifer Sinclair Curtis, University of California, Davis}

Jennifer Sinclair Curtis is Distinguished Professor of Chemical Engineering and Dean of the College of Engineering at University of California, Davis. She is a Fellow of AAAS, AIChE and ASEE. Professor Curtis is a recipient of a Fulbright Senior Research Scholar Award, AIChE's Thomas-Baron Award in Fluid-Particle Systems, the AIChE's Fluidization Lectureship Award, AIChE's van Antwerpen Award, the American Society of Engineering Education's Chemical Engineering Lectureship Award, the Eminent Overseas Lectureship Award by the Institution of Engineers in Australia, and ASEE's Sharon Keillor Award for Women in Engineering, and the NSF Presidential Young Investigator Award. She has served on the National Academy of Engineering's Committee on Engineering Education and has participated in two NAE Frontiers of Research Symposia (2003 and 2008). She currently serves as co-Chair of the National Academies' Chemical Sciences Roundtable and member of the National Academies' Board on Chemical Sciences and Technology.

Professor Curtis received a B.S. in Chemical Engineering from Purdue University (1983) and a PhD in Chemical Engineering from Princeton University (1989). Prior to joining UC Davis in 2015, she was Distinguished Professor of Chemical Engineering and Associate Dean for Research at the University of Florida. She has also served on the faculty of Carnegie Mellon University and Purdue University. At CMU she received the college-wide Ladd Research Award and at Purdue she was named University Faculty Scholar.

Professor Curtis' research on the development of multiphase CFD models and discrete element method models for particulate flow. Her multiphase flow models, based on first principles granular kinetic theory, were the first to be adopted bysoftware package ANSYS Fluent. ANSYS is the largest producer of simulation software used by 96 of the 100 biggest industrial companies and over 40,000 customers. Her multiphase flow models are also included in the CFD Research Corporation CFD software package and the open-source CFD code (OpenFOAM).

\section{Dr. Jason E. Butler, University of Florida}




\title{
Work in Progress: Peer-Led Research Methods Workshop for First-Year Ph.D. Students (Student Paper)
}

\author{
Vincent J. Tocco ${ }^{1}$, Kevin E. Buettner ${ }^{1}$, Madeline Sciullo², Jennifer S. Curtis ${ }^{3}$ \\ and Jason E. Butler ${ }^{1}$ \\ ${ }^{1}$ Department of Chemical Engineering, University of Florida, Gainesville FL; ${ }^{2}$ Department of Electrical and \\ Computer Engineering, University of Florida, Gainesville FL; ${ }^{3}$ Department of Chemical Engineering, University of \\ California, Davis, Davis, CA
}

\begin{abstract}
A team of experienced $\mathrm{Ph} . \mathrm{D}$. candidates developed and facilitated discussion in a semester-long weekly workshop that outlined basic research skills for a small cohort of first year doctoral students in Chemical Engineering. Session topics included professionalism, analyzing research articles, scientific writing mechanics, and designing presentation slides, among others. The peerled approach provided an informal classroom setting, which fostered interactivity and stimulated students' willingness to participate in discussions. Incorporating such a workshop in other departments or universities could greatly benefit all fledgling researchers and their principal investigators by boosting the students' productivity and research quality as they adapt to the process of doing research. Such a workshop also offers senior Ph.D. candidates an opportunity to improve their pedagogical methods.
\end{abstract}

\section{Keywords}

Graduate Education, Research Skills, Professional Development, Work-in-Progress, Tricks of the Trade

\section{Introduction}

Many first-year doctoral students struggle to acclimate to the rigor, independence, and uncertainty of conducting academic research. Incoming Ph.D. students are coming from a classroom setting, where the skills needed to succeed in research are rarely discussed. Thus, when these students begin their doctoral research, these skills are often learned by trial-and-error or careful observation and emulation of more accomplished researchers.

Successful researchers (in all fields) display aptitude in the following areas: finding and understanding relevant literature, writing proposals and journal articles, and delivering technical presentations. Students are typically expected to develop these skills through the "apprenticeship" of working with an advisor. However, some advisors might assume that their new students have already learned these skills. Other advisors might struggle to find time to train their students while simultaneously fulfilling their other duties as a professor. Under such constraints, teaching research basics is often perceived to be low-priority.

To address this problem, some universities have incorporated faculty-taught graduate courses or seminars into their curricula for first-year graduate students ${ }^{1-3}$. These courses address important topics for young researchers, such as a re-introduction of the scientific method, scientific writing 
of proposals and papers, and ethical considerations. For departments with such structured courses, new graduate students develop their research skills together, which saves the students' advisors time in teaching them basics individually. Such a system also avoids frustration due to lost productivity in the early stages of their studies.

Many of these ideas are independent of the field of study, hence they can be taught by any thoughtful instructor who has experienced the research process. As graduate students ourselves, we are uniquely equipped to teach the course for two main reasons. One, because we are peers, the classroom setting will be informal and more likely to foster interactivity, which has been suggested to appeal to millennial learners in multiple contexts ${ }^{4,5}$. Two, we have experienced the struggles of graduate school more recently than professors, and therefore the topics are fresher in our minds.

Here, we created a semester-long, seminar-style course that outlines basic research skills for first-year graduate students seeking research degrees. This course was completely designed and taught by a team of three senior graduate students, drawing inspiration from already-existing methods and courses ${ }^{1-3,6-8}$, the recommendations of faculty members, and our own experiences. The peer-led approach gives the senior graduate students an opportunity to improve pedagogical skills while still providing the information that similar courses at other universities provide.

\section{Workshop Format and Structure}

Workshop sessions lasted 50 minutes and occurred at the same time each week in a classroom setting. Attendance was not compulsory; of the twelve new Ph.D. students admitted to the Department of Chemical Engineering at the University of Florida in fall 2017, five attended consistently, with two more attending sparingly. Each session covered a different topic (Table 1) and was presented as a peer-directed discussion, rather than a lecture. We incorporated active learning techniques (such as think-pair-share) and interactive activities (such as a drawing a concept map of research tasks).

\begin{tabular}{|c|l|}
\hline Week & \multicolumn{1}{c|}{ Title } \\
\hline 1 & How to Succeed in Graduate School \\
\hline 2 & Getting Started with Research Methods \\
\hline 3 & Finding and Organizing Literature \\
\hline 4 & Reading and Critiquing Literature \\
\hline 5 & Data Processing and Visualization \\
\hline 6 & Scientific Writing I: Developing Style \\
\hline 7 & Scientific Writing II: The Submission Process \\
\hline 8 & Designing Presentations and Posters \\
\hline 9 & Communication and Networking \\
\hline 10 & Ethics/Keeping a Lab Notebook \\
\hline
\end{tabular}

Table 1. Topics discussed in each week's workshop.

For example, in Session 4, "Reading and Critiquing Literature", we (as facilitators) first provided anecdotes of the frustrations we experienced while reading our first research papers. We then asked the first year students to describe their strategy in reading research papers. In general, they 
read from start to finish, pausing to conduct internet searches on unfamiliar terms. We shifted the discussion to explain how an experienced graduate student might first evaluate a research paper before deciding to read it (by skipping ahead to the last paragraph of the introduction and carefully considering the figures), then concluded by offering general strategies. For another example, in Session 7, "Scientific Writing II: The Submission Process", we demonstrated where to find a journal's Instructions for Authors, and simulated the steps of the often-overlooked submission process (reformatting the manuscript, writing a cover letter, choosing appropriate keywords, disclosing conflicts of interest and author contributions, among others).

We asked students to complete a short ( $<30$ minutes) "homework assignment" prior to each session. For example, before Session 3, "Finding and Organizing Literature", we wrote a tutorial about how to install and use reference-managing software. Before Session 5, "Data Processing and Visualization", we provided students with a sample dataset, and asked them to prepare a plot suitable for publication. Before Session 6, "Scientific Writing I: Developing Style", we asked students to edit a sample of flawed scientific writing.

\section{Benefits to Students and Facilitators}

We had intended to measure the impact of this course with a short survey (approved by the University of Florida Institutional Review Board) designed to quantify the students' attitudes about the course. Unfortunately, we were unable to collect enough data to make statistically significant conclusions. However, anecdotal feedback from students was overwhelmingly positive.

Participating in this workshop allowed students to discuss the common "unwritten rules" of research, as presented by their peers (who are actively performing research). As a result, they began their research careers with a better understanding of how and where to start and stay organized. This workshop also benefitted new students' labs, because it centralized and outsourced the training of new graduate students. As a result, more time became available for lab-specific training by lab managers.

Participating as a facilitator in this workshop presents a unique opportunity for graduate students who aspire to an academic career. Others have noted that completion of a Ph.D. itself does not necessarily develop teaching and mentorship skills ${ }^{9}$, therefore students could benefit from extra teaching experience. Additionally, the planning of the sessions and exercises inspired the facilitators to become metacognitively aware of their own research methods and processes.

\section{Reflections and Future Work}

The diversity of research areas, career goals, and personalities among the three facilitators contributed greatly to the intellectual merit of the workshop. Inclusion of these multiple perspectives ensured that the workshop topics were broadly applicable. Admittedly, some of our advice was a matter of personal opinion; therefore, further exemplifying the value of including several experienced viewpoints in the sessions.

The peer-led aspect of this workshop was likely a significant portion of its success; however, we acknowledge the potential benefits of including faculty in the discussions as well. Ideally, future 
iterations of this workshop will continue to be peer-led, but under the guidance of a faculty coordinator to ensure continuity in subsequent years.

Although our first cohort was small, we felt that our workshop had a big impact in acclimating the new students to the mindset of performing academic research. We have begun the process to incorporate this workshop formally as a one-credit elective in the University of Florida chemical engineering curriculum. The long-term vision is to recommend the course strongly for all new $\mathrm{Ph} . \mathrm{D}$. students, while still allowing research-oriented undergraduates to participate as well. 


\section{Acknowledgements}

The authors wish to acknowledge the intellectual contributions of Dr. Carlos Rinaldi, Dr. Chelsey Simmons, and Dr. Hans van Oostrom. We also acknowledge the invaluable insight of Dr. Mark Law, who participated in the discussion during Session 7, "The Submission Process."

\section{References}

1 Burrows VA, Beaudoin SP. A graduate course in research methods. Chem Eng Educ. 2001;35(4):276-279.

2. Holles JH. A graduate course in theory and methods of research. Chem Eng Educ. 2007;41(4):226-232.

3. Ollis D. Catalyzing the student-to-researcher transition: research initiation and professional development for new graduate students. Chem Eng Educ. 2016;50(4):221-229.

4. Carpente J. Using Web-based technologies to reach and engage millennial students in calculus. ASEE Annu Conf Expo Conf Proc. 2009. https://www.scopus.com/inward/record.uri?eid=2-s2.069249167216\&partnerID=40\&md5=3b52a4590353331438821b451f02283e.

5. Waters C. Teaching the millennial student, adapting the learning framework for material science. In: American Society for Engineering Education. ; 2009.

6. Harrison RG, Nollert MU, Schmidtke DW, Sikavitsas VI. The Research Proposal in Bioengineering Courses. Chem Eng Educ. 2006;40(4):323-326.

7. Aucoin MG, Jolicoeur M. Is there room in the graduate curriculum to learn how to be a grad student? An approach using a graduate-level biochemical engineering course. Chem Eng Educ. 2009;43(4):306-312.

8. Hill PJ. Teaching entering graduate students the role of journal articles in research. Chem Eng Educ. 2006;40(4):246-250.

9. Wankat PC. Pedagogical Training and Research in Engineering Education. Chem Eng Educ. 2008;42(4):203-210.

\section{Vincent J. Tocco}

Vincent (VJ) Tocco is a $5^{\text {th }}$ year Ph.D. candidate in Chemical Engineering at the University of Florida. In addition to his research in cellular mechanics, he enjoys mentoring undergraduates and high school students. After winning the Ray Fahien Award of Outstanding Teaching Assistant (awarded by the University of Florida Department of Chemical Engineering) twice, VJ decided to pursue a teaching career as a lecturer, and is currently actively seeking positions.

\section{Kevin Buettner}

Kevin Buettner is a $5^{\text {th }}$ year Ph.D. candidate in Chemical Engineering at the University of Florida. He is working under the guidance of Prof. Jennifer S. Curtis in the area of granular flows, where he has won multiple awards for his technical presentation prowess. Within the lab, Kevin has actively mentored undergraduate researchers and helped them through the process of applying and preparing for graduate school. Upon graduating in August 2018, Kevin is searching for industry positions in the area of process modeling.

\section{Madeline Sciullo}

Madeline (Maddie) Sciullo is a $4^{\text {th }}$ year Ph.D. candidate in Electrical and Computer Engineering at the University of Florida. Her research is centered on her advisor's device and process simulator, Dr. Mark Law Florida Object Oriented Device/Process Simulator (FLOOD/FLOOPS). She has three major projects of which the applications are radiation effects on AlGaN/GaN High Electron Mobility Transistors (HEMTs), mechanical stress effects of Silicon based Hall magnetic 
sensors, and $\mathrm{pH}$ chemical/biological sensors on open-gated GaN-based HEMTs. Maddie plans to graduate in August 2018 and is pursuing postdoctoral opportunities.

\section{Jennifer S. Curtis}

Jennifer Sinclair Curtis is a Distinguished Professor of Chemical Engineering and Dean of the College of Engineering at University of California, Davis. She is a Fellow of ASEE, AAAS, and AIChE. Professor Curtis is a recipient of ASEE's Chemical Engineering Lectureship Award and ASEE's Sharon Keillor Award for Women in Engineering. She has served on the National Academy of Engineering's Committee on Engineering Education and as Associate Dean for Undergraduate Education at Purdue University.

\section{Jason E. Butler}

Dr. Butler is a research and education specialist in the area of soft matter dynamics and, as a Professor of Chemical Engineering at the University of Florida, has been educating students on transport phenomena, professional development, and more for over fifteen years. Areas of active research include rheology, particulate suspension dynamics, and polyelectrolyte dynamics in microfluidic devices. 